\title{
OPPORTUNISTIC USE OF A WOOL-LIKE ARTIFICIAL MATERIAL AS LINING OF TIT (PARIDAE) NESTS
}

\author{
Joanne Surgey ${ }^{1}$, Christopher R. Du Feu ${ }^{2}$ and D. Charles Deeming ${ }^{3,4}$ \\ 19 Southwell Rise, Giltbrook, Nottingham, NG16 2WQ, United Kingdom \\ ${ }^{2} 66$ High Street, Beckingham, Nottinghamshire, DN10 4PF, United Kingdom \\ ${ }^{3}$ School of Life Sciences, University of Lincoln, Riseholme Park, Lincoln, LN2 2LG, United Kingdom
}

\begin{abstract}
The lining material is a key element of bird nests, serving primarily as insulation for the adult, eggs, and/or chicks, but collection of such material has an energetic cost. Our study investigated the nest-building effort of four species of tit (Paridae) in an English wood by quantifying the use of colored wool-like artificial material in nest lining from 2000 to 2010. We recorded the distances that birds carried the material from source to nest for each nest as an indirect measure of the energetic cost of collecting nest material to individual birds. Birds did not always use nest material from the nearest source to their nest, and some birds collected material from two, three or four well-separated sources. There was no detectable color preference in choice of material, and few birds traveled more than $200 \mathrm{~m}$ to gather the material. Use of the material appeared to depend on the species. Within defined areas around material dispensers not all individual Great Tits (Parus major) used the artificial material, and, for all species examined, the proportion of birds using the material declined with increasing distance between source and nest. Use of artificial material suggested that selection of nest materials was probably opportunistic but also reflected the preference of these species for a wool-like nest lining.
\end{abstract}

Key words: artificial nest material, Cyanistes caeruleus, nest construction, Parus major, Periparus ater, Poecile palustris.

\section{Uso Oportunista de un Material Artificial Tipo Lana como Revestimiento de los Nidos de los Paridae}

Resumen. El material de revestimiento es un elemento clave del nido de las aves, que sirve principalmente de aislamiento para el adulto, los huevos y/o los pichones, pero la colecta de este tipo de material tiene un costo energético. Nuestro estudio investigó el esfuerzo de construcción del nido de cuatro especies de Paridae en un bosque Inglés mediante la cuantificación del uso de material artificial coloreado tipo lana en el revestimiento del nido desde 2000 a 2010. Registramos las distancias que las aves transportaron el material desde la fuente hasta el nido para cada nido, como una medida indirecta del costo energético de colectar material para el nido para cada ave individual. Las aves no siempre usaron material para el nido de la fuente más cercana, y algunas aves colectaron material de dos, tres o cuatro fuentes bien separadas. No hubo una preferencia de color detectable en la selección del material y pocas aves se desplazaron más de $200 \mathrm{~m}$ para juntar el material. El uso del material parece depender de la especie. Dentro de áreas definidas alrededor de dispensadores de material, no todos los individuos de Parus major usaron el material artificial, y de todas las especies examinadas, la proporción de aves que usaron el material disminuyó con un aumento en la distancia entre la fuente y el nido. El uso de material artificial sugirió que la selección del material para el nido fue probablemente oportunista, pero también reflejó la preferencia de estas especies por un revestimiento del nido tipo lana.

\section{INTRODUCTION}

Despite the importance of nests in avian reproduction (see Hansell 2000) it is only recently that research has begun to provide insight into the value placed on the various materials used in construction of these structures. Hence, although many different materials of plant and particularly animal origin are used in the innermost lining layer of nests (Hansell 2000), their exact roles in nest construction are only now being explored.

Nest-lining materials appear to have several roles depending on the species. They can be used to conceal eggs, particularly during the egg-laying phase, e.g., down feathers lining Common Eider (Somateria mollissima) nests (Fast et al. 2010). Also, as the lining is soft and, at first, springy, it is expandable, allowing for nestling growth (Hansell 2000). Nest linings derived from plants may also be important in control of parasites (Wimberger 1984, Clark and Mason 1985, Mennerat et al. 2009) or microbes (Baggott and Graeme-Cook 2002). However, a major function of the nest lining is associated with its insulating capacity (Soler et al. 1998).

Insulation of the eggs and the incubating adult may be particularly important if ambient temperatures are low-Haftorn and

Manuscript received 18 July 2011; accepted 16 October 2011.

${ }^{4}$ E-mail: cdeeming@lincoln.ac.uk

The Condor, Vol. 114, Number 2, pages 385-392. ISSN 0010-5422, electronic ISSN 1938-5422. (c) 2012 by The Cooper Ornithological Society. All rights reserved. Please direct all requests for permission to photocopy or reproduce article content through the University of California Press's Rights and Permissions website, http://www.ucpressjournals.com/ reprintInfo.asp. DOI: $10.1525 /$ cond.2012.110111 
Reinertsen (1985) showed a significant increase in the oxygen consumption of incubating Blue Tits (Cyanistes caeruleus) when nest-box temperature was reduced. Hence, the insulative properties of a nest may reflect temperatures when it was built and so correspond to the needs of the adult rather than of the eggs or chicks (Britt and Deeming 2011, Mainwaring et al. unpubl. data). Studies have suggested that well-insulated nests reduce the energetic cost of incubation for parents, affect incubation behavior, and positively affect nestlings' growth rate (Skowron and Kern 1980, Lombardo et al. 1995, Soler et al. 1998, Cresswell et al. 2003, McGowan et al. 2004). Maintenance of egg temperature during incubation or rearing may be critical because it may affect offspring fitness (Hepp et al. 2006, Pérez et al. 2008). Moreover, in cold climates the nests of some species appear to have become so well insulated as to have affected the humidity levels within the nest and the gas conductance of the eggshells (Deeming 2011).

Collection of material appropriate for a nest lining should, therefore, be an important component in avian reproduction, but there must be a trade-off between construction of a "perfect" nest and the time and energy expended looking for the ideal materials (Hansell and Ruxton 2002, McGowan et al. 2004). The costs of nest building have recently been shown to be higher than was previously realized. For example, Cliff Swallows (Petrochelidon pyrrhonota) use more energy during nest construction than in any other aspect of rearing the young (Withers 1977). African Village Weavers (Ploceus cucullatus graueri) fly an average total distance of $34 \mathrm{~km}$ in the construction and lining of a single nest (Collias and Collias 1967). The availability of nest materials and the distances traveled to collect them could impose a significant energetic cost and also increase the risk of predation while the adult is searching for material (Soler et al. 1998). Food availability may be a limiting factor in nest-construction behavior in general because supplementary feeding of Blue Tits increased nest mass (Mainwaring and Hartley 2009). In the Australian Reed Warbler (Acrocephalus australis) supplementary feeding increased the number of "type II" nests a male built in his territory; these nests are not used for reproduction and are considered to be a sexual signal (Berg et al. 2006).

Our study aimed at assessing the value placed on an insulative material in terms of nest construction as determined by the distances that individuals traveled to collect nest material. In a woodland, we provided artificial woollike material of four different colors, which was subsequently found in nests of four species of tits (Paridae) that used nest boxes at the site. Other species not nesting in boxes may have used the material, but we did not investigate that. We assumed that greater distances between the source of the material and the nest were directly positively correlated with the physical effort of collecting the material and hence indicate the value that the birds placed on that resource. Furthermore, the amount of material collected may also reflect the value placed on the resource by the bird during nest construction. If distance traveled to collect material did correspond to the effort required to collect it, then we predicted that birds using the most artificial material in their nest lining should be traveling the shortest distances to collect it.

\section{METHODS}

This field study was carried out in Treswell Wood, Nottinghamshire $\left(53^{\circ} 18^{\prime} \mathrm{N}, 00^{\circ} 51^{\prime} \mathrm{W}\right)$. The site is ancient coppice woodland covering $\sim 48$ ha and is managed as a nature reserve (Deeming and du Feu 2011). The wood is a thick " $\mathrm{C}$ " in shape with its long axis running for $\sim 1200 \mathrm{~m}$ north-south and its east-west axis having maximum and minimum widths of $\sim 650 \mathrm{~m}$ and $\sim 250 \mathrm{~m}$, respectively. We used data from nest-box records covering the years 2000-2010, although no data were collected during 2001 owing to restrictions on visiting Treswell Wood during an outbreak of foot and mouth disease. We analyzed data from the nests of the Great Tit (Parus major), Blue Tit, Coal Tit (Periparus ater), and Marsh Tit (Poecile palustris) found in nest boxes provided in the woodland.

In late February or early March, we filled four plastic mesh dispensers with wool-like artificial cushion stuffing and hung them on tree branches approximately $2.5 \mathrm{~m}$ from the ground. These dispensers were available prior to the breeding season and during the period when birds were seeking out foraging sites within the wood. We left them in position until the end of the nesting season (June). The material was originally white but using cold-water fabric dye we permanently dyed some samples green, red, or yellow. During the years 2000 and 2002 to 2007, the four dispensers were sited in different parts of the wood but never the same color in the same place in two successive years. By dispersing four dispensers through the wood we aimed to increase the number of birds that had opportunity to use the material and hence to increase the sample size. The use of four different colors allowed determination of which dispenser the lining in any nest had been taken from and thus the distance traveled could be calculated. From 2008 to 2010 we placed the four dispensers together in one central location to ascertain whether the birds preferred to use particular colors. In all cases we recorded the locations of the dispensers with a GPS receiver.

We recorded the location of each nest box in the wood with a GPS receiver and during the breeding season examined every box to ascertain the species nesting and how much of the artificial nest material had been used. Four observers were trained to grade use of the nest material by giving each a number as follows: 1 - some lining in the nest, but only seen with deliberate inspection; 2-enough nest lining to be obvious; 3 - over half the nest lining of the material; 4-all or nearly all the lining of the material. If possible without risking the incubating female's desertion, we read the number on its leg band ( $20 \%$ of nests) (Deeming and du Feu 2011).

Using Pythagoras' theorem, we calculated the distances between lining dispenser and nest box from GPS-derived 
Ordinance Survey grid references of boxes and dispensers. The accuracy of these measurements is typically within $5 \mathrm{~m}$, locations being recorded during winter when the leaf canopy does not weaken the signals. Any inaccuracies have little effect on the calculated mean distances but may increase the variance slightly. Where we found more than one color of material in one nest, we calculated the weighted mean distance for that nest from the coded amount of each color of material used as the weight.

Over the study, the numbers of Great Tit nests being built and incorporating the artificial nest material were such that we could determine the probability that any bird was using the artificial nest material within certain distances from the dispenser. The data for the other three species were too limited to be used in this kind of analysis. Each year, we plotted the locations of all Great Tit nests on a scale map of Treswell Wood, then superimposed the locations of those nests including each of the four colors of nest material. Using a compass, we drew a series of concentric circles of radii of 50,100, 150, and $200 \mathrm{~m}$ around the location of each dispenser. We expressed the number of nests with the artificial nest material as a proportion of the total nests within the circle. For each year we calculated the mean proportions for each circle for the four colors of artificial material. Then we averaged the data, separately for 2000-2007, when the locations of the dispensers varied from year to year, and for 2008-2010, when all four dispensers were placed in the same central location.

\section{STATISTICAL ANALYSIS}

We organized the frequencies for nests or species in contingency tables and compared them with chi-squared tests. Mean annual proportions of the nests with artificial material were tested with Kruskal-Wallis tests. We investigated distances traveled by the various nest materials by analysis of variance, square-root transforming data prior to analysis (Fowler et al. 1998:83-89) to normalize their distribution (as checked with Kolmogorov-Smirnov tests). For the Great Tit, we analyzed the effect of distance to dispenser and location of the dispenser with two-way ANOVA after arcsine transformation in order to control for proportional data (Fowler et al. 1998: 83-89). For these analyses we used PSAW (www.spss.com), and we report all results as means $\pm \mathrm{SE}$.

\section{RESULTS}

\section{NUMBERS OF NESTS AND SPECIES INVOLVED}

The total number of nests of tits recorded during this study period was 1034 from four species: the Great Tit contributed the largest proportion of the nests $(56.3 \%)$, followed by the Blue, Coal and Marsh Tits $(37.4 \%, 4.4 \%$, and $1.9 \%$, respectively). Over the same period 244 nests were found to contain the colored nest material (Table 1). The Great Tit contributed highest proportion of these nests with artificial material, although at $72.5 \%$ this was much higher than the proportion of the total nests in the wood. The Marsh Tit also contributed a relatively greater proportion of the nests with artificial material $(4.1 \%)$ than their contribution to the total nests would have predicted. The Blue and Coal Tits contributed relatively smaller proportions of the nests that contained the artificial nest material $(20.9 \%$ and $2.5 \%$, respectively). This distribution of nests with artificial material was significantly different from that expected from the total nests $(4 \times 2$ contingency table: $\left.\chi_{3}^{2}=48.7, P<0.001\right)$.

On average $22.3 \%(\mathrm{SE}=2.8 \%)$ of nests per year were found containing artificial nest material. The percentage of nests with the material increased from 2000 to 2005 but declined thereafter (Fig. 1). A further decrease was seen in 2008,

TABLE 1. Numbers of nests incorporating colored nest material by each of the four species studied. Numbers in parentheses indicate the total number of nests of that species found that year in Treswell Wood.

\begin{tabular}{lccccc}
\hline \hline Year & Total & Great Tit & Blue Tit & Coal Tit & Marsh Tit \\
\hline 2000 & $8(75)$ & $5(25)$ & $3(45)$ & $0(4)$ & $0(1)$ \\
2002 & $17(69)$ & $9(24)$ & $6(36)$ & $0(6)$ & $2(3)$ \\
2003 & $24(108)$ & $20(57)$ & $3(44)$ & $0(6)$ & $1(1)$ \\
2004 & $38(110)$ & $26(55)$ & $9(47)$ & $2(7)$ & $1(1)$ \\
2005 & $47(134)$ & $35(86)$ & $9(41)$ & $1(5)$ & $2(2)$ \\
2006 & $45(160)$ & $33(102)$ & $10(47)$ & $1(7)$ & $1(4)$ \\
2007 & $22(108)$ & $17(65)$ & $4(40)$ & $0(2)$ & $1(1)$ \\
2008 & $13(97)$ & $8(52)$ & $2(37)$ & $1(6)$ & $2(2)$ \\
2009 & $9(85)$ & $7(54)$ & $1(27)$ & $1(2)$ & $0(2)$ \\
2010 & $21(88)$ & $17(62)$ & $4(23)$ & $0(0)$ & $0(3)$ \\
Total & $244(1034)$ & $177(582)$ & $51(387)$ & $6(45)$ & $10(20)$ \\
Mean per & & & & & $0.592(0.472)$ \\
year (SD) & $0.223(0.089)$ & $0.295(0.112)$ & $0.129(0.071)$ & $0.130(0.167)$ & \\
\hline
\end{tabular}




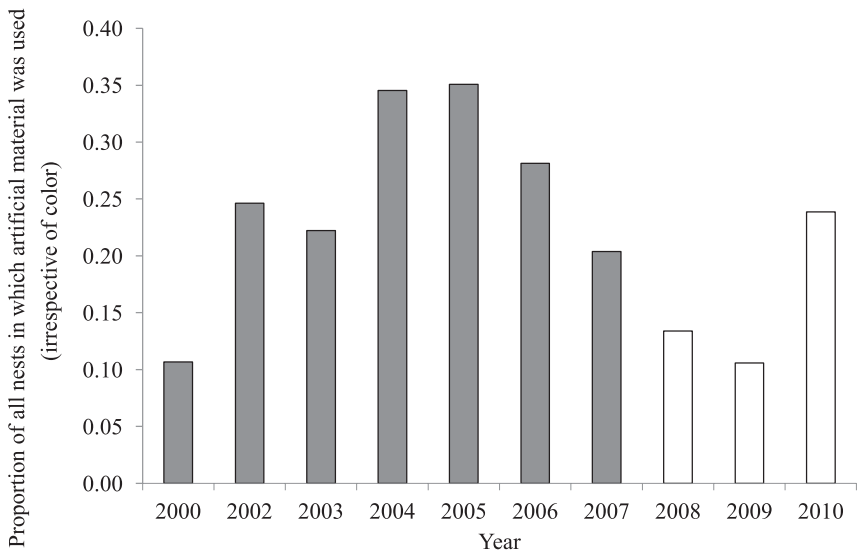

FIGURE 1. Proportion of total nests in which the colored nesting material was used, all four species combined. Gray columns, years when dispensers of the artificial nest material were located at different places in the wood; white columns, years when the four colors were located in a central dispenser.

the first year that all four dispensers were placed together in one location. The decline continued in 2009 but was markedly reversed in 2010 (Fig. 1). The mean annual proportions of the nests with artificial material (Table 1 ) varied significantly by species (Kruskal-Wallis test: $\chi_{3}^{2}=9.6, P=0.022$ ) with the mean proportions highest for the Marsh and Great Tits. From 2000 to $2007,29(14.4 \%$ of the total with the material) nests had more than one color compared with $22(\mathrm{SE}=51.2 \%)$ nests from 2008 to 2010.

Band numbers were available for only 53 females out of 244 nests, numerically more for the Blue Tit $(n=40)$, but for $50 \%$ of all Coal Tit nests (3/6) and all of the Marsh Tit nests (10/10). Repeated use of artificial material from one year to another was observed in only three Marsh Tits and two Blue Tits.

Table 2 shows the number of nests, for each species, that contained 1, 2, 3, or 4 colors of the artificial material. Use of one color was commonest, followed by use of two colors, but chi-squared analysis showed that there was no significant departure from the proportions of each species using different numbers of colors of the artificial materials expected from the numbers of nests of each species $(4 \times 4$ contingency table: $\left.\chi_{9}^{2}=11.3, P>0.05\right)$.

TABLE 2. Number of nests per species that had different numbers of colors within the lining.

\begin{tabular}{lrrrr}
\hline \hline & \multicolumn{4}{c}{ Number of colors } \\
\cline { 2 - 5 } Species & 1 & 2 & 3 & 4 \\
\hline Great Tit & 136 & 31 & 7 & 3 \\
Blue Tit & 45 & 5 & 0 & 1 \\
Coal Tit & 4 & 1 & 1 & 0 \\
Marsh Tit & 8 & 1 & 0 & 1 \\
\hline
\end{tabular}

TABLE 3. Total numbers of nests per species in which colors were used.

\begin{tabular}{lcccc}
\hline \hline Species & Green & Red & White & Yellow \\
\hline Great Tit & 59 & 83 & 55 & 33 \\
Blue Tit & 11 & 20 & 16 & 12 \\
Coal Tit & 1 & 0 & 3 & 4 \\
Marsh Tit & 4 & 2 & 4 & 4 \\
\hline
\end{tabular}

The use of color was to allow us to distinguish how far material was carried from the dispenser, but it also allowed determination of color preference. Overall, red was the most popular color and yellow was least favored (Table 3), but there was no color preference by any of the species $(4 \times 4$ contingency table: $\chi_{9}^{2}=14.5, P>0.05$ ).

\section{FACTORS AFFECTING DISTANCES TRAVELED TO COLLECT NEST MATERIAL}

Irrespective of color, the distances between dispensers of artificial material and the nest boxes were not normally distributed (Fig. 2) and had a mean of $167.8 \mathrm{~m}(\mathrm{SE}=7.1 ; 95 \%$ confidence interval $=14.0 ;$ mode $=43.1 ; n=311$ ), which represented the distances covered for each instance of color in each box. The greatest distance that artificial material was carried was $860 \mathrm{~m}$ for yellow material carried to a nest box by a Great Tit.

Color did not significantly affect the mean distance between the dispenser and the nest box $\left(F_{3,307}=0.673, P>0.05\right)$. Therefore, we adjusted the data to produce a weighted average, based on the amount of material in the nest, for the distances that artificial material of each color had taken from the dispenser to each nest box. This reduced the sample size to the 244 nests. We also recalculated the total amount of artificial material per nest (as the sum of the codes for each color used truncated to a maximum value of 4). The average distance between the dispenser and the nest box was $161.7 \mathrm{~m}$ $(\mathrm{SD}=119.4 ; 95 \% \mathrm{CI}=15.1)$, and, although the distance for the Coal Tit nests was greater (mean $=239 \mathrm{~m})$, ANOVA of squareroot-transformed weighted distances showed no significant effect of species on the distance traveled from the dispenser to the nest box $\left(F_{3,240}=1.081, P>0.05\right)$.

By contrast, the greatest distances traveled were for the least amount of material, and the least mean distance was for when the lining material was all artificial material (Fig. 3). One-way ANOVA of transformed data showed that there was a significant effect of amount of material observed $\left(F_{3,240}=6.34, P<0.001\right)$. Two-way ANOVA of transformed data showed that the mean distance was significantly affected by the amount of material in the nest $\left(F_{3,229}=4.93, P=0.02\right)$, but there was no effect of species $\left(F_{3,229}=2.107, P>0.05\right)$ and no significant interaction $\left(F_{8,229}=1.224, P>0.05\right)$. 


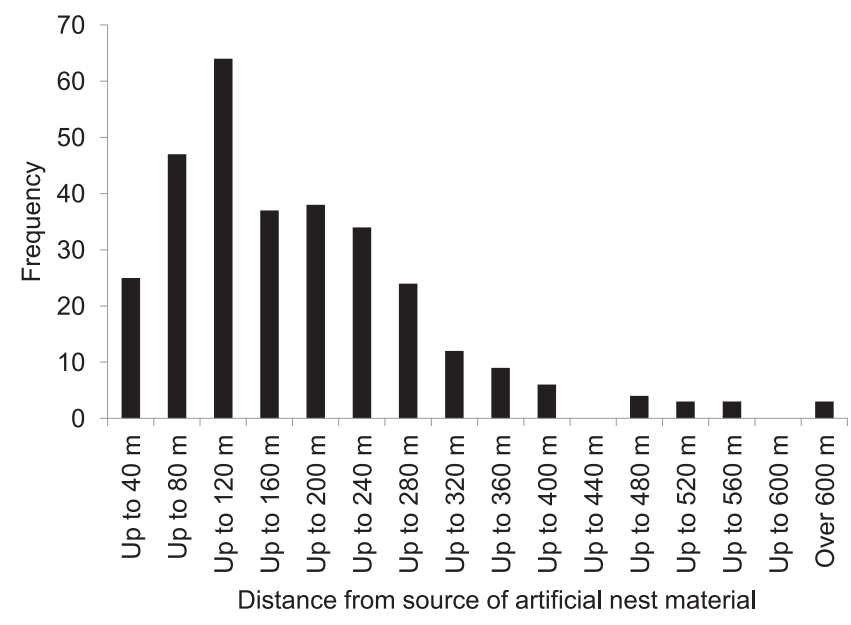

FIGURE 2. Frequency of nests incorporating artificial nest material as a function of distance from dispenser (all species, colors, and locations of dispensers combined).

The proportion of Great Tit nests that incorporated artificial nest material depended on the distance from the dispenser and the location of the dispenser (according to year). From 2000 to 2007, when the dispensers were dispersed through the woodland, $50 \%$ of the nests included the artificial material if the box was within $50 \mathrm{~m}$, but this proportion declined steadily to $20 \%$ of the nests at $150 \mathrm{~m}$ and $200 \mathrm{~m}$ from the dispenser (Fig. 4). By contrast, when the artificial material was available at only one place the proportion of nests with the material was above $45 \%$ for up to a distance of $150 \mathrm{~m}$ and then declined sharply to $25 \%$ of nests at $200 \mathrm{~m}$ (Fig. 4). Two-way ANOVA showed that distance had a significant effect on the proportion of nests $\left(F_{3,32}=7.42, P=0.001\right)$. There was a significant effect of dispenser location $\left(F_{1,32}=4.99, P=0.033\right)$ but no significant interaction $\left(F_{3,32}=1.73, P=0.180\right)$.

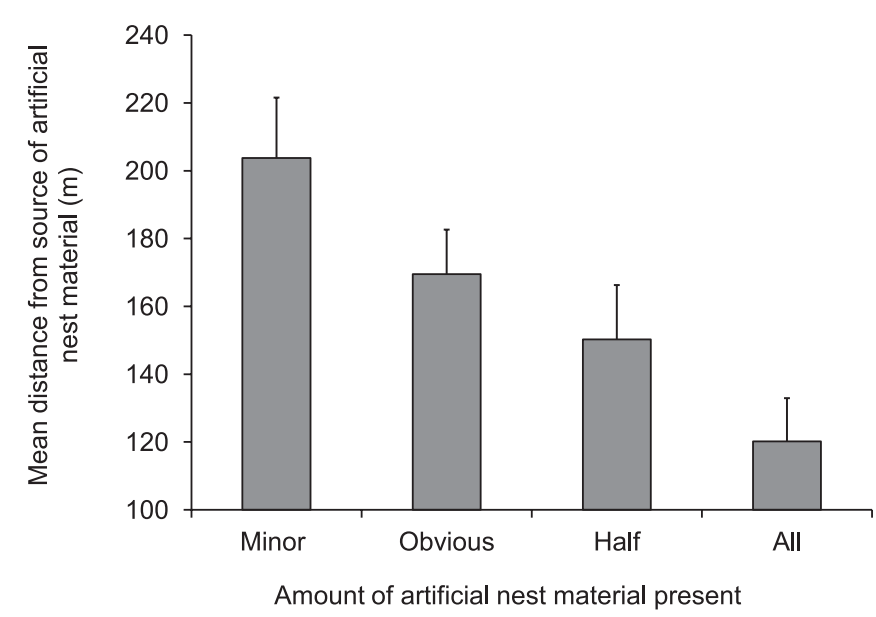

FIGURE 3. The amount of material (+SE) carried from the dispenser to nest box irrespective of color, species, or location of the dispensers.

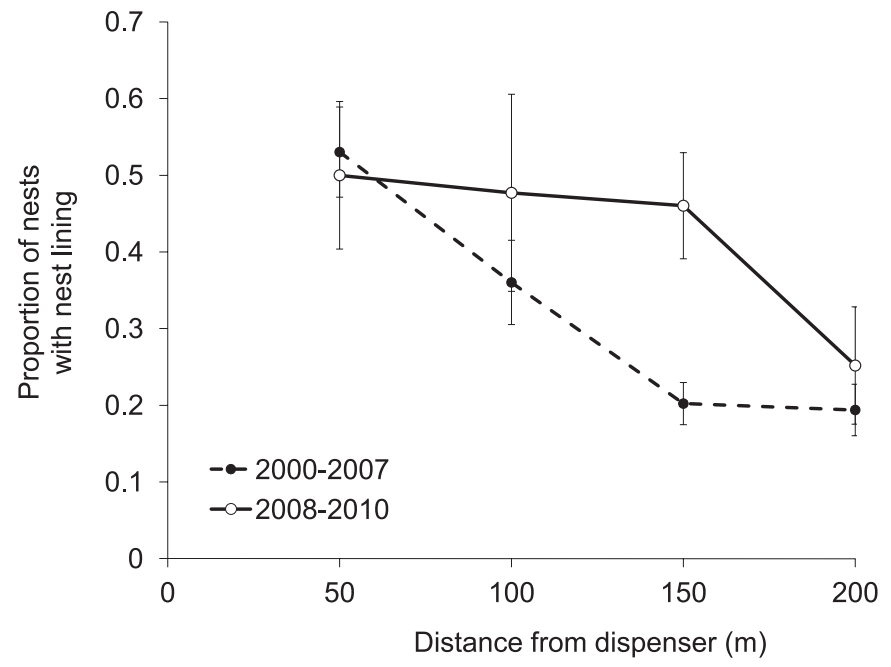

FIGURE 4. Mean proportion ( \pm SE) of Great Tit nest boxes containing artificial nest material (irrespective of color) at different distances from the dispensers. Black circles, years when the four dispensers were dispersed through the wood (2000-2007); white circles, years when the four dispensers were clustered at one location (2008-2010).

\section{DISCUSSION}

We found that these species of tits incorporated wool-like artificial nest material into their nests, although overall relatively few individuals used the resource and this use varied by species. Some individuals traveled considerable distances from their nest, but the birds exhibited no color preference. Our hypothesis that the amount of material in a nest would be greatest in those nests nearest to the dispensers was supported. The proportion of Great Tit nests into which artificial material was incorporated depended not just on the distance to the nest box but also on the location of a dispenser.

\section{USE OF ARTIFICIAL MATERIALS IN NESTS}

We did not investigate the other materials the birds used to construct their nests because we did not consider them important in this context. However, nest-construction materials are usually described only in qualitative terms (Skutch 1976, Collias and Collias 1984, Hansell 2000), and there are few detailed analyses of the proportions of the different materials incorporated into the various structural components of the nest. Detailed descriptions of some passerines' nests are available (Kern and van Riper 1984, Blem and Blem 1994, Elts 2005, Crossman et al. 2011), and nests of the Great and Blue Tits differ (Britt and Deeming 2011). Use of artificial nest materials in nests has been reported (Hansell 2000, Berg et al. 2006) but not systematically reviewed. There is anecdotal evidence of rapid use of novel artificial material; for instance, during the Second World War, within two weeks of its first deployment, aluminium foil dropped over Jersey from bombers to confuse 
enemy radar was used by Common Blackbirds (Turdus merula) in their nests (Le Ruez 2007). Interestingly, humanderived material is used in over $80 \%$ of Black Kite (Milvus migrans) nests, although its use varies with the bird's age and has been interpreted to be territorial threat to conspecifics (Sergio et al. 2011). By contrast, artificial material was a very small part of the overall material of Blue and Great Tit nests (Britt and Deeming 2011). Although tits used wool-like artificial material when available in our study, the extent to which this reflects an element of convenience for the birds because the material was supplied in mesh containers at fixed locations is unclear. However, not all tits nesting in Treswell wood took advantage of the material, and numbers of birds using the material varied over the study period. Even within $50 \mathrm{~m}$ of the dispenser only half of the Great Tits used the material.

We found that Great Tits used the artificial material more often, and traveled greater distances for it, from 2008 to 2010 when the material was present in one location. Marsh Tits also seemed to use the artificial material more frequently, although this species was relatively uncommon in Treswell Wood. Blue and Coal Tits appeared to be less interested in using the material in their nests. Although there may have been interspecific interactions at the dispensers akin to those seen at feeding stations (Carrascal and Moreno 1992), it is probably more likely that these species do have a preference for particular types of materials. The relatively lower incidence of use of artificial material by Blue Tits may reflect their preference for feathers as a lining material (Perrins 1979, Britt and Deeming 2011), and Great and Marsh Tits may be more willing to accommodate the wool-like artificial material in their nests. Feathers do appear to be preferred by some small passerines, including the Long-tailed Tit (Aegithalos caudatus), Common Chaffinch (Fringilla coelebs) and Tree Sparrow (Passer montanus; Hansell and Ruxton 2002, McGowan et al. 2004, Britt and Deeming, 2011). An interesting extension to our study would be provide a variety of nest materials, for example, feathers and real fur, to determine whether species do have a real preference when given a choice.

\section{CHOICE OF LINING MATERIALS IN NESTS}

Mechanical strength or physical properties may be important in choice of materials for a nest (Slagsvold 1989, Heenan and Seymour 2011), but insulation properties may be more critical when it comes to the lining. Hansell (2000) reported that corvids tend to use plant-derived materials in the lining layer but the smaller tyrant flycatchers use plant down and feathers and the finches (Fringillidae) use fur or hair together with rootlets. Coarser plant materials have poorer insulative properties than animal fur or feathers (Hilton et al. 2004). Larger species, with higher thermal inertia, may be less reliant on highly insulative lining materials than are smaller species. Even among the tits the amount of lining material in Blue Tit and Great Tit nests differs, as can the materials used (Britt and
Deeming 2011). In common with many small birds (Møller 1984, Hansell and Ruxton 2002), the smaller Blue Tit prefers to use feathers rather than the fur used by the larger Great Tit (Perrins 1979, Britt and Deeming 2011), but it is unknown whether this difference reflects the materials' different insulative properties (Hilton et al. 2004).

That the artificial material was wool-like in appearance may mean that the tits recognized that, like real wool, it could serve some kind of insulative role and it would be appropriate for the nest lining. Color was unimportant, but whether the texture was really important requires further investigation. If insulation is an important role for a lining layer then it should be greater in nests of smaller species or species living in cold environments (Crossman et al. 2011, Mainwaring et al. unpubl. data). The type (Mainwaring and Hartley 2008) or amount (Britt and Deeming 2011) of material used may also vary. Despite its presumed importance in the nest very few studies have investigated the role that the nest lining has in the function of the nest. Mainwaring and Hartley (2008) showed that the mass of the nest lining inversely is correlated with the first egg date, and Britt and Deeming (2011) showed that in Blue Tit nests the amount of animal derived material is affected by ambient temperature.

Given that less than a quarter of the nests we studied contained the artificial material we believe it is likely that choice of this nest material was opportunistic - the birds found it during their normal daily routine and took material as was required. This conclusion is supported by the fact that the proportion of nests with the artificial material within them varied from year to year, and that there was a low incidence of repeated use of material by individuals in successive years. Britt and Deeming (2011) found the Blue and Great Tits to use wool in their nests opportunistically, according to their proximity to sheep. Similarly, on Hawaii, van Riper (1977) found that passerines' use of wool depended on the intricacy of the nest and whether wool was present within a bird's territory. Only the Elepaio (Chasiempis sandwichensis) and the Hawaii Amakihi (Hemignathus virens) traveled any distance to collect wool for the body of their nests (van Riper 1977).

In our study, other factors may have influenced the birds' opportunities to encounter the artificial material. Territorial behavior by individual birds immediately adjacent to a dispenser may have limited access to the material. However, the location of the dispensers and the distances traveled meant that many individuals had to fly across several territories to reach their nest boxes and yet material was present in their nests. Such excursions across established territories may have reflected other activities of the birds, such as searches for suitable environmental sources of calcium for egg formation (Wilkin et al. 2009), which would have increased the chances of an individual female encountering the dispenser. Use of colored material could prove useful in further studies of these species' territoriality and activity during the breeding season. 


\section{COLOR PREFERENCES}

In birds, the best example of color preference during reproduction is in the constructions by bowerbirds (Ptilonorynchidae), but this is related to a structure that is built to attract a mate rather to serve as a nest (Hansell 2000). To date, few studies have examined the color preferences of birds during nesting. The tits we studied did not prefer any color when using the artificial nest material, although green was most commonly used. Use of green material in nests may reflect the general use of plant material in nest construction, or it may be related to the insecticidal characteristics of certain plants (Menneret et al. 2009), or it may may be a sexual signal, as shown in the European Starling (Sturnus vulgaris; Brouwer and Komdeur 2004). Muth and Healy (2011) found adult Zebra Finches' (Taeniopygia guttata) choice of color of nest material to be related to their reproductive experience. Although green material was chosen more commonly than brown, males changed their preference according to their reproductive success. That we observed no color preference is, therefore, not surprising because it is difficult to envisage how most colors would confer any advantage to the birds. White may have been an exception because for species such as the tits that lay generally white eggs, a white nest lining might act as crypsis and reduce the likelihood of predation. In a preliminary study, birds given the choice of white or black dog fur removed more of the former from a dispenser and brought it to nest boxes (Deeming, unpubl. data). There may be color preference in those species such as the Longtailed Tit that use materials on the outer surface to disguise their nests, but this has not been investigated.

Muth and Healy (2011) reported that male Zebra Finches not only select the color of nest materials but that this color preference seems to persist in the next generation. Our data were insufficient to ascertain whether use of the artificial nest material by individual birds persisted from one year to the next, nor was it possible to determine whether the preference for nest-lining material was passed down to the offspring. Given the distances between dispensers during the period 2000-2007, it would seem that individuals that incorporated more than one color into their nests showed a preference for the artificial material and were prepared to travel to collect it.

\section{CONCLUSIONS}

Overall, it is probable that the use of artificial nest material was dependent on the preference for wool-like material by the species involved, but it was also opportunistic in that individuals would use the material if they encountered it. The availability of material appeared to be associated with the locations of the dispensers and the distances moved by the birds. Use of artificial nest material is partially species dependent, which may reflect the species' preference for texture, but is not dependent on color. In nests some distance from the dispenser the use of material was not consistent and probably reflected the birds taking advantage of a resource that they encountered almost at random. By contrast, nests in which the lining was all artificial were located relatively close to the dispenser, suggesting that the birds were taking advantage of a reliable source of a useful material. Whether selection of artificial material affects the time, or energy, needed to line a nest is not known, nor are the effects on reproductive success known, but both of these could be easily investigated. Our study suggests that it is possible to test the nest-material preference of passerine species and it may be possible to manipulate nest composition experimentally by addition of materials.

\section{ACKNOWLEDGMENTS}

Many thanks go to the many volunteers, particularly Richard du Feu, Phil May, John Clark, John Bartley, John Black, Dan Bardsley and Gill Bardsley, who monitor the nest boxes in Treswell Wood, and to the Nottinghamshire Wildlife Trust for permission to use Treswell Wood. We thank the two anonymous reviewers of a previous version of this paper for their constructive criticisms.

\section{LITERATURE CITED}

Baggott, G. K., and K. Graeme-Cook. 2002. Microbiology of natural incubation, p. 179-191. In D. C. Deeming [ED.], Avian incubation: behaviour, environment and evolution,. Oxford University Press, Oxford, England.

Berg, M. L., N. H. Beintema, J. A. Welbergen, and J. Komdeur. 2006. The functional significance of multiple nest-building in the Australian Reed Warbler Acrocephalus australis. Ibis 148:395-404.

Blem, C. R., AND L. B. Blem. 1994. Composition and microclimate of Protonontary Warbler nests. Auk 111:197-200.

BRITT, J., AND D. C. DeEMING. 2011. First egg date and air temperature affect nest construction in Blue Tits Cyanistes caeruleus but not in Great Tits Parus major. Bird Study 58:78-89.

Brouwer, L., AND J. Komdeur. 2004. Green nesting material has a function in mate attraction in the European Starling. Animal Behaviour 67:539-548.

Carrascal, L. M., And E. Moreno. 1992. Proximal costs and benefits of heterospecific social foraging in the Great Tit, Parus major. Canadian Journal of Zoology 70:1947-1952.

Clark, L., AND J. R. MASON. 1985. Use of nest material as insecticidal and anti-pathogenic agents by the European Starling. Oecologia 67:169-176.

Collias, N. E., AND E. C. Collias. 1984. Nest building and bird behavior. Princeton University Press, Princeton, NJ.

Collias, N. E., AND E. C. Collias. 1967. A quantitative analysis of breeding behavior in the African Village Weaverbird. Auk 84:396-411.

Cresswell, W., S. Holt, J. M. Reid, D. P. Whitfield, And R. J. MelLANBY. 2003. Do energetic demands constrain incubation scheduling in a biparental species? Behavioural Ecology 14:97-102.

Crossman, C. A., V. G. Rohwer, and P. R. Martin. 2011. Variation in the structure of bird nests between northern Manitoba and southeastern Ontario. PLoS One 6(4):e19086.

DeEming, D. C. 2011. Importance of nest type on the regulation of humidity in bird nests. Avian Biology Research 4:23-31.

DeEming, D. C., AND DU FEU, C. R. 2011. Long term patterns in egg mortality during incubation and chick mortality during rearing in three species of tits in an English woodland. Bird Study 58:278-290.

ELTS, J. 2005. On the nest material of the Willow Warbler: a quantitative analysis. Hirundo 18:31-33. 
Fast, P. L. F., H. G. Gilchrist, and R. G. Clark. 2010. Nest-site materials affect nest-bowl use by Common Eiders (Somateria mollissima). Canadian Journal of Zoology 88:214-218,

Fowler, J., L. Cohen, AND P. Jarvis. 1998. Practical statistics for field biologists. Wiley, Chichester, England.

HAFTORN, S., AND R. E. REINERTSEN. 1985. The effect of temperature and clutch size on the energetic cost of incubation in a free-living Blue Tit (Parus caeruleus). Auk 102:470-478.

Hansell, M. 2000. Bird nests and construction behaviour. Cambridge University Press, Cambridge, England.

Hansell M., AND G. D. RuXTON. 2002 An experimental study of the availability of feathers for avian nest building. Journal of Avian Biology 33:318-320.

HeEnan, C. B., AND R. S. Seymour. 2011. Structural support, not insulation, is the primary driver for avian cup-shaped nest design. Proceedings of the Royal Society B 278:2924-2929.

Hepp, G. R., R. A. Kennamer, AND M. H. Johnson. 2006. Maternal effects in Wood Ducks: incubation temperature influences incubation period and neonate phenotype. Functional Ecology 20:307-314.

Hilton, G. M., M. H. Hansell, G. D. Ruxton, J. M. Reid, and P. MONAGHAN. 2004. Using artificial nests to test importance of nesting material and nest shelter for incubation energetics. Auk 121:777-787.

KERN, M., AND C. VAN RIPER. 1984. Altitudinal variations in nests of the Hawaiian honeycreeper Hemignathus virens virens. Condor 86:443-454.

Le Ruez, A. M. 2007. Jersey occupation diary. Seaflower Books, St. Helier, Jersey.

Lombardo, M. P., R. M. Bosman, C. A. Faro, S. G. Houtteman, AND T. S. KLUISZA. 1995. Effect of feathers as nest insulation on incubation behavior and reproductive performance of Tree Swallows (Tachycineta bicolor). Auk 112:973-981.

Mainwaring, M. C., AND I. R. Hartley. 2008. Seasonal adjustments in nest cup lining in Blue Tits Cyanistes caeruleus. Ardea 96:278-282.

Mainwaring, M. C., AND I. R. Hartley. 2009. Experimental evidence for state-dependent nest weight in the Blue Tit, Cyanistes caeruleus. Behavioural Processes 81:144-146.
McGowan, A., S. P. Sharp, And B. J. Hatchwell. 2004. The structure and function of nests of Long-tailed Tits Aegithalos caudatus. Functional Ecology 18: 578-583.

Mennerat, A., P. Perret, And M. M. Lambrechts. 2009. Local individual preferences for nest material in a passerine bird. PLoS One 4:1-6.

MøLleR, A. P. 1984. On the use of feathers in birds' nest: predictions and tests. Ornis Scandinavica 15:38-42.

Muth, F., And S. D. Healy. 2011. The role of adult experience in nest building in the Zebra Finch, Taeniopygia guttata. Animal Behaviour 82:185-189.

Pérez, J. H., D. R. Ardia, E. K. Chad, And E. D. Clotfelter. 2008. Experimental heating reveals nest temperature affects nestling condition in Tree Swallows (Tachycineta bicolor). Biology Letters 4:468-471.

Perrins, C. M. 1979. British tits. Collins, London.

Sergio, F., J. Blas, G. Blanco, A. Tanferna, L. López, J. A. Lemus, AND F. HiRALDo. 2011. Raptor nest decorations are a reliable threat against conspecifics. Science 331:327-330.

SKOWRON, C., AND M. KERN. 1980. The insulation in nests of selected North American songbirds. Auk 97:816-824.

SkUTCH, A. F. 1976. Parent birds and their young. University of Texas Press, Austin, TX.

Slagsvold, T. 1989. On the evolution of clutch size and nest size in passerine birds. Oecologia 79:300-305.

Soler, J. J., A. P. Møller, AND M. SOLER. 1998. Nest building, sexual selection and parental investment. Evolutionary Ecology 12:427-441.

VAN RIPER III, C. 1977. The use of sheep wool in nest construction by Hawaiian birds. Auk 94:646-651.

Wilkin, T. A., A. G. Gosler, D. Garant, S. J. Reynolds, and B. C. Sheldon. 2009. Calcium effects on life-history traits in a wild population of the Great Tit (Parus major): analysis of long-term data at several spatial scales. Oecologia 159:463-472.

WiMBERGER, P. H. 1984. The use of green plant material in bird nests to avoid ectoparasites. Auk 101:615-618.

Withers, P. C. 1977. Energetic aspects of reproduction by the Cliff Swallow. Auk 94:718-725. 